\title{
Political Deliberation in the Blogosphere: The Case of the 2009 Portuguese Elections
}

\author{
Rui Pedro Lourenço ${ }^{1,2}$ \\ ${ }^{1}$ INESC Coimbra, Rua Antero de Quental, 199, \\ 3000 Coimbra, Portugal \\ ${ }^{2}$ Faculty of Economics, University of Coimbra, Av. Dias da Silva. 165, \\ 3000 Coimbra, Portugal \\ ruiloure@fe.uc.pt
}

\begin{abstract}
In 2009, a unique Portuguese electoral cycle comprised european, local, and national elections. During the three month non-stop campaign period, more than a hundred experienced bloggers, supporters of the three main political parties, created three non party-sponsored blogs. These blogs were the focal point of the political blogosphere during that period and ceased their activities at the end of the electoral campaign, thus providing a unique opportunity to better understand the political blogosphere. Web mining techniques were used to obtain data concerning the visits to those blogs (from Sitemeter) and the blog's content itself (posts, comments, and links). Data suggests that blog readers don't look for different points of view, blog commentators usually limit themselves to one blog, bloggers do not comment on other blogs other than their own, and relatively few links exist between all three blogs. These results undermine the idea that the political blogosphere can enhance the deliberative character of the public sphere.
\end{abstract}

Keywords: Political blogosphere; Public sphere; Deliberation.

\section{Introduction}

Political talk is an essential part of democracy [1]. It can occur in the privacy of our homes, in the inner circle of friends and family, and constitutes the basic public participation tool of common citizens. However, political talk in restricted environments suffers from limitations with respect to the availability of information, the exposition to opposing views and arguments, and the possibility to influence policy formulation and public decision processes.

In order to overcome these limitations it is essential that contemporary democratic societies nurture public arenas where citizens may engage in political talk in a free and autonomous manner. These public arenas relate to the concept of public sphere which is generally used to designate "the social space between the state and civil society" [2] where "something approaching public opinion can be formed" [3] after "exposure to a sufficient amount of information, and also to an appropriately wide and diverse range of options" [4]. 
In this context, deliberation is a process by which individual preferences and points of view change due solely to the force of the better argument, that is, without coercion [5]. As a social process, deliberation can be viewed as a communicative process which involves the serious consideration of arguments in favor and against a certain proposition [6], and by which participants are willing to change their preferences and points of view [7]. Putting aside some demands for discursive rationalism required by Jürgen Habermas [3] to qualify discussion in the public sphere as deliberation, some authors characterize the deliberative process by its result, "the endogenous change in preferences resulting from communication" [8].

The importance of deliberation in contemporary democratic systems is emphasized by deliberative democrats such as John Dryzek when he states: "the essence of democracy itself is now widely taken to be deliberation, as opposed to voting, interest aggregation, constitutional rights, or even self-government" [7].

The Internet, and particularly the blogosphere, may contribute decisively to the improvement and enlargement of the public sphere, providing the necessary conditions for the development of public deliberative processes, including freedom of speech and association.

The nature of the blogosphere, where a significant part of what is written is devoted to criticize other people's opinion, is considered an indication of its deliberative potential [9]. Also, the structure of blogs sets them apart from the traditional media and suggest that they are an adequate platform to foster political deliberation: readers may create content related to the posts they read and other people's comments; it is possible to create links between posts and comments which express opposing points of view and arguments; blogs maintain a list of other blogs (blogrolls) which usually include blogs from different political areas [9, 10].

Nevertheless, concerns remain about the potential of these digital media to fragment and polarize the public sphere, and that, in reality, political blogs readers and writers tend to isolate themselves from opposing points of view and arguments [4]. American cultural blogs, for instance, seem to follow this pattern [11]. They specialize in a unique form of art and subculture and adopting well defined points of view, thus mimicking some of the most influential political blogs [11].

These concerns are justified by empirical studies that analyzed the content and blogroll of influential American political blogs and concluded that the vast majority of the links connected blogs and bloggers who share the same ideological area $[12,13]$. This seem to confirm that it is not enough to provide structural conditions for meaningful deliberation: to consider the political blogosphere as truly deliberative it is necessary that blog contributors and readers are willing to be exposed to opposing arguments, to discuss them with others and reflect upon them. Otherwise the blogosphere effect on the public sphere will be mitigated and will limit itself to reproduce what empirical studies reveal about the "real life": citizens prefer to discuss political issues with those who share their values and points of view, trying to avoid conflict situations [14].

So, it is important to the quality of democracy to understand if the Internet, and the blogosphere in particular, can contribute to reduce this natural aversion to confront ideas due, for instance, to the possibility to allow anonymity and avoid face-to-face contact between the participants in a discussion. 
The goal of this work is twofold. First, it aims at enhancing the knowledge about the deliberative nature of the political blogosphere. Previous research efforts focused on structural and qualitative content analysis of blog contributions (written posts, comments, and links). This work tries to complement previous research by assessing the behavior of blog readers, those who just observe the debate without contributing to it [14], through quantitative analysis of blog visiting data. Second, it aims at better understanding the Portuguese political blogosphere and assess its deliberative nature.

\section{Research Methodology}

In 2009, Portugal witnessed a unique political cycle which comprised three, very close, electoral events: the European Parliament election in July, the General election (National Assembly and Government) in September, and the Local Authorities election in October.

Also, at that time the ruling party had an absolute majority in the National Parliament and, because of that, there was some acrimony between opposing political parties. As it would be expected, the existing political climate and the concentration of electoral events fostered very vivid discussions both on traditional media and on the Internet.

During that period of time, supporters from the three main political parties created three non-official party blogs. These blogs were created in the end of July, lasted until the end of September, and were mainly focused on the General Election. They gathered a total of 114 authors, including some of the most prominent political bloggers, and became the reference for the political blogosphere during that period of time.

The coincidence of such political (electoral) events and the creation of these three dedicated blogs provided the ideal opportunity to analyze the Portuguese political blogosphere.

To better understand the data, the process used to collect it, and the analysis made, the following terminology will be used throughout the remaining of the text:

- Authors or Bloggers: those that created each of the three blogs and therefore have the possibility to write posts and create links in the blog they "belong to". Naturally and author of a specific blog might also create comments in his/her own blog and on any of the other blogs;

- Visitors or Blog readers: all those that accessed the blogs, including authors from one of the three blogs and commentators.

Web mining techniques were used to collect all data (covering the period when the blogs were active - approximately 2 months) from the 3 blogs including post text, post author, post links, comments text, and comments author (nickname and URL ${ }^{1}$ ). Additionally, visiting data (IP address and access time) was collected from Sitemeter ${ }^{2}$ regarding each blog. Due to technical difficulties only data regarding blog visits in the 15 days prior to the General election were collected and analyzed (during general electoral campaign). Contrary to blog content, which is available for analysis still today, visiting data by Sitemeter has to be collected in a real-time way, as only the last 100 accesses are publicly available at any given moment.

\footnotetext{
${ }^{1}$ Uniform Resource Location.

${ }^{2}$ www. sitemeter.com
} 
Table 1 presents the characterization of the three blogs analyzed, including its name, URL and political affiliation ${ }^{3}$.

Table 1. Blog's characterization

\begin{tabular}{lrrr}
\hline Blog name & URL & Party & Political spectrum \\
\hline SIMPlex & simplex.blogs.sapo.pt & PS & Center-left (ruling party) \\
Jamais & jamais.blogs.sapo.pt & PSD & Center-right (main opposition party) \\
Rua Direita & ruadireita.blogs.sapo.pt & CDS-PP & Right-wing \\
\hline
\end{tabular}

\section{Data Collected}

Table 2 presents an overview of the number of authors (bloggers) registered on each blog, and the number of posts, comments and links produced.

Table 2. Blogs' content

\begin{tabular}{lrrrr}
\hline & Nr authors & Nr posts & Nr comments & Nr links \\
\hline SIMPlex & 41 & 1285 & 6638 & 1990 \\
Jamais & 33 & 1000 & 2729 & 1112 \\
Rua Direita & 40 & 908 & 1142 & 938 \\
\hline TOTAL & 114 & 3193 & 10509 & 4040 \\
\hline
\end{tabular}

This general data is further detailed in the next sections.

\subsection{Visiting and Electoral Data}

Each blog was associated with one of the three main Portuguese political parties. Table 3 shows the electoral score (number of votes) of each party and the number of corresponding blog visits, as recorded by Sitemeter, during the time the blogs were active. Using just these parties (and blogs) as the universe of total number of votes, it is possible to calculate the percentage of votes and blog visits for each party/blog and compare them.

Table 3. Number of votes (political parties) and number of visits (blogs)

\begin{tabular}{lrrrrr}
\hline Blog/Party & \multicolumn{2}{c}{ Votes (party) } & \multicolumn{2}{c}{ Visits (blog) } & Dif. \\
& $\mathrm{N}^{4}$ & $\%^{5}$ & $\mathrm{~N}^{6}$ & $\%$ & (p.p.) \\
\hline SIMPlex/PS & 2068665 & $48,0 \%$ & 187583 & $51,7 \%$ & $+3,7$ \\
Jamais/PSD & 1646097 & $38,2 \%$ & 132044 & $36,3 \%$ & $-1,8$ \\
Rua Direita/CDS-PP & 592064 & $13,8 \%$ & 43404 & $12,0 \%$ & $-1,7$ \\
\hline TOTAL & 4306826 & $100,0 \%$ & 363031 & $100,0 \%$ & \\
\hline
\end{tabular}

${ }^{3}$ Although political party affiliation was explicitly stated in all three blogs, all of them also stated that these were non-official party blogs.

${ }^{4}$ Source: http: //aeiou.visao.pt/mapa-dos-resultados-finais= f530790 (30/09/2009)

${ }^{5}$ These values were calculated just considering the number of votes in these three parties.

${ }^{6}$ Source: Sitemeter (30/09/2009). SiteMeter defines a "visit" as a set of page views originating from the same IP address within a 30 minute time interval. 
According to this data, the difference (measured in percentage points) between political parties votes and blog visits ranges from $-1,8$ to $+3,7$.

Data collected from Sitemeter regarding each visit of a reader to each blog included the IP address ${ }^{7}$ of the computer where the visit was initiated and the time at which that visit was initiated.

The concept of reading event was defined to assess how many blogs each visitor read when accessing the blogosphere. For that matter, visits were considered in 30 , 60, 90, and 120 minute periods. For instance, visits coming from the same IP address and occurring in less that 120 minutes apart were considered as being part of the same reading event by the same reader (visitor).

Table 4 presents the number of reading events considered for each of the time periods considered, and the percentage of those events that involved just one, two, or all three blogs.

Table 4. Number of blogs visited on the same reading event

\begin{tabular}{lrrrr}
\hline & $30 \mathrm{~min}$. & $60 \mathrm{~min}$. & $90 \mathrm{~min}$. & $120 \mathrm{~min}$. \\
\hline Nr of reading events (total) & 73192 & 65070 & 59862 & 56130 \\
\hline Just visiting 1 blog & $84 \%$ & $82 \%$ & $81 \%$ & $80 \%$ \\
Visiting 2 blogs & $14 \%$ & $16 \%$ & $17 \%$ & $17 \%$ \\
Visiting all 3 blogs & $2 \%$ & $2 \%$ & $2 \%$ & $3 \%$ \\
\hline
\end{tabular}

If we consider reading events grouping visits from the same IP address in 120 minutes interval, we can see that, under these conditions, blog readers visited only one blog in $80 \%$ of the reading events, they visited two blogs in $17 \%$ of the reading events, and they visited all three blogs in only $3 \%$ of the reading events.

\subsection{Comments Data}

One important indicator of a deliberative political blogosphere is cross commenting: bloggers (authors) associated with a particular blog write comments in another blog.

Table 5 presents the number of bloggers associated with each blog and the number of them which made comments in other blogs.

Table 5. Blog authors and comments in other blogs

\begin{tabular}{lrrr}
\hline & $\begin{array}{r}\text { Nr of } \\
\text { authors }\end{array}$ & $\begin{array}{r}\text { Nr of authors who wrote } \\
\text { comments on another blog }\end{array}$ & $\begin{array}{r}\text { Nr of authors who wrote } \\
\text { comments on both other blogs }\end{array}$ \\
\hline SIMPlex & 41 & 11 & 1 \\
Jamais & 33 & 8 & 2 \\
Rua Direita & 40 & 4 & 0 \\
\hline TOTAL & 114 & 23 & 3 \\
& $100 \%$ & $20 \%$ & $3 \%$ \\
\hline
\end{tabular}

${ }^{7}$ Several limitations exist regarding these data. Those limitations and their impact on analysis will be addressed in section 5 . 
Data shows that $20 \%$ of all the blog authors (114) wrote comments on another blog other than his/her own, and only $3 \%$ wrote comments on both the other two blogs.

Another way to analyze cross comments is to consider how many comments were made by bloggers outside their own blog. Table 6 presents the total number of comments written by bloggers of each blog (in all three blogs) and how many of those comments were written in another blog (other than the blogger's own blog).

Table 6. Number of comments written by bloggers of each blog

\begin{tabular}{lrrr}
\hline $\begin{array}{l}\text { Bloggers } \\
\text { from }\end{array}$ & $\begin{array}{r}\text { Total number of } \\
\text { comments written }\end{array}$ & $\begin{array}{r}\text { Comments written in } \\
\text { another blog }\end{array}$ \\
\hline SIMPlex & 1277 & 65 & $5 \%$ \\
Jamais & 353 & 21 & $6 \%$ \\
Rua Direita & 287 & 4 & $1 \%$ \\
\hline
\end{tabular}

Collected data shows that very few comments were made by authors of a certain blog in another blog. For instance, among the 1277 comments written by "SIMPLex" bloggers only $65(5 \%)$ were made either in "Jamais" or "Rua Direita". As for bloggers from the other blogs the numbers are in the same magnitude.

We can also analyze how many of the comments written in each blog were made by authors (bloggers) of the other blogs. Table 7 shows, for each blog, the origin of its comments.

Table 7. Origin of the comments on each blog

\begin{tabular}{lrrrrr}
\hline & Number of comments & \multicolumn{4}{c}{ Written by bloggers from: } \\
& on each blog & SIMPlex & Jamais & Rua Direita & Other \\
\hline SIMPlex & 6638 & $18,3 \%$ & $0,3 \%$ & $0,0 \%$ & $81,5 \%$ \\
Jamais & 2729 & $2,2 \%$ & $12,2 \%$ & $0,1 \%$ & $85,6 \%$ \\
Rua Direita & 1142 & $0,5 \%$ & $0,4 \%$ & $24,8 \%$ & $74,3 \%$ \\
\hline
\end{tabular}

According to this data, very few comments made on each blog were attributed to bloggers from any of the other two blogs. The vast majority of comments on each blog were either made by their own bloggers or by other visitors (including anonymous ones).

If we consider the entire universe of blog readers (not just bloggers from the three blogs) we might have a complementary perspective. Table 8 presents the number and percentage of blog readers that wrote comments exclusively in one of the blogs, in two of the blogs and in all three of them.

Table 8. Number authors who wrote comments in one, two, or three blogs

\begin{tabular}{lrr}
\hline Authors of comments & $\mathrm{Nr}$ & $\%$ \\
\hline In just one blog & 1272 & $80 \%$ \\
In two blogs & 255 & $16 \%$ \\
In three blogs & 56 & $4 \%$ \\
\hline TOTAL & 1583 & \\
\hline
\end{tabular}


This data suggests that the majority of blog readers $(80 \%)$ wrote comments in just one blog. By contrary, only $4 \%$ of all identifiable blog readers (those having the same nickname and URL) wrote comments in all three blogs.

\subsection{Links Data}

Another useful data to assess the deliberative nature of the political blogosphere is the one related with links made from a particular blog to one of the other blogs, as shown in Table 9.

Table 9. Posts linking to one of the other blogs

\begin{tabular}{lrrr}
\hline & $\begin{array}{r}\text { Total number } \\
\text { of posts }\end{array}$ & \multicolumn{2}{r}{ Posts linking to other blogs } \\
& 1285 & 125 & $10 \%$ \\
\hline SIMPlex & 1000 & 117 & $12 \%$ \\
Jamais & 908 & 75 & $8 \%$ \\
Rua Direita & & \\
\hline
\end{tabular}

Data shows that between $8 \%$ and $12 \%$ of posts in one blog had links to one of the other two blogs.

\section{Discussion}

Using the data collected it is possible to address the questions presented next.

\subsection{Can the Blogosphere Be Used to "Predict" Electoral Results?}

Some traditional polling techniques rely on fixed phone interviews to collect raw data with which electoral projections are made. But the use of fixed phones is steadily decreasing and rising mobile phone penetration rate makes it more difficult to collect such data. This prompts concerns about electoral projections accuracy and suggests the possibility that other media might be better to collect such data. Among others, the blogosphere, as a forum for political debate, could be considered an alternative way to know citizen's political preferences and predict electoral results.

Data from Table 3 suggests that blog visiting numbers came close to actual electoral results (in percentage of this universe). This does not mean that it would be possible to predict electoral results this way, but it seems to confirm that the blogosphere might indeed provide a barometer to political preferences.

Further research is necessary to develop the procedures to collect and analyze blogosphere data. It is necessary to address issues such as visiting numbers manipulation: it would be very easy to manipulate visiting numbers once it was known that those numbers were being used to make electoral projections. It is also essential to take into account the socio-demographic specifics of political bloggers and blog readers and, more generally, the limitations of Internet access and digital divide. These and other difficulties make it very challenging to create a reliable procedure to produce electoral projections from political blogosphere data. 


\subsection{How Deliberative Is the Portuguese Political Blogosphere?}

In a truly deliberative public sphere, participants seek to confront opposing points of view before forming their own opinion. Structurally, the blogosphere provides a facilitating discussion environment since it allows bloggers to comment each other posts and link to them. By writing comments in another blog, bloggers engage in a discussion with the author of the post they are commenting, and therefore contribute to the exchange of arguments and points of view.

However, data collected suggests that very few bloggers made comments on one of the other blogs (Table 5). Not surprisingly then, very few comments in each blog where made by bloggers from one the other blogs (Tables 6 and 7). It is, of course, possible that some comments were written anonymously (or under a nickname) and were not associated with a particular blogger. However, bloggers from these particular blogs were all well known and identified themselves as authors of their posts, which makes it not very plausible that they would not do the same with their comments.

Instead of commenting on other blogs, authors have the possibility to confront ideas and exchange arguments by linking their posts to posts and comments in the other blogs. Again, data indicates that the number of posts with links to one of the two other blogs ranges between $8 \%$ and $12 \%$ (Table 9).

Not all references to posts and comments from other blogs are expressed by crossed comments or linking. Sometimes the author of a post merely gives indication on his/her text that he/she is participating in a wider debate. Nevertheless, these last two results seem to indicate that either there is not that much interaction between political bloggers, or that the linking mechanism that blogs make available are not being properly used, thus making it more difficult for a reader to follow the discussion.

Previous work that analyzed the political blogosphere limited their scope to blog structure and content (blogroll, post and comment analysis) and blog writers (post authors) behavior. This work seeks to contribute to a broader perspective by including blog readers' behavior in the analysis.

According to Table $8,80 \%$ of all identifiable visitors who wrote comments in all three blogs just wrote comments on a single blog, $16 \%$ wrote comments on two different blogs, and $4 \%$ wrote comments on all three blogs.

Finally, this work also tried to assess the behavior of blog readers that don't even write posts or comments using visiting data collected by Sitemeter. Analysis show that if we consider 120 minute intervals between recorded visits, the vast majority of blog visitors (80\%) accesses only one of the three blogs. On the opposite side, just $3 \%$ visits all three blogs in a 120 minute interval (Table 4).

If we consider these two results together, they indicate that even blog readers do not seek to confront different opinions and points of view. This might be just a similar behavior to the bloggers involved, or it might be a consequence of the lack of structuring (limited use of post links) by post authors (bloggers).

\section{Conclusion}

The blogosphere is a continuously evolving environment: every day new blogs are created and old ones end. Bloggers cease their collaboration in one blog and start 
writing in another. Commentators use different nick names and "hide" behind anonymity. Some blog readers simple accompany the discussion without intervening. This makes it very difficult to analyze the political blogosphere and assess its deliberative nature and the impact it has on the public sphere and political life. The ultimate research challenge regarding the political blogosphere is then to evaluate its real impact on the points of view and voting behavior of bloggers, blog commentators, blog readers, and society in general.

The 2009 Portuguese electoral cycle, and the political environment that surrounded it, led to the creation of three non-official blogs affiliated with the three main political parties. This provided a unique opportunity to study the Portuguese political sphere and contribute to assess if indeed it plays a role in enhancing a deliberative public sphere. This study broaden the work done on previous studies by, among others, specifically including in the analysis the behavior of blog commentators and readers using Sitemeter statistics.

Results must be considered cautiously as there were several technical limitations to the process of data collecting and analysis. For instance, blog visiting data from Sitemeter's free version includes only the first 3 octets of the IP address. Firewalls, and $\mathrm{NAT}^{8}$ mechanisms could mask the real IP address of blog visitors. Analysis of visiting data considered a visiting profile where blog readers would access blogs within 120 minutes interval: a larger interval would perhaps identify visits to more blogs originating in the same IP address but that could be attributed to dynamic IPs or simply to the fact that different users use the same computer. Also, to establish the authorship of different comments by the same visitor, we considered matching nicknames and URL when provided. This means that, although some take great pride in their nickname and use it as "trademark", others simply jump from one nickname to another thus making it very difficult to correctly match comment authors.

Despite all these limitations, this study found no evidence that the potential of the blogosphere structure is being used to promote a truly deliberative arena, thus confirming previous research: there is limited interaction between bloggers from different ideological areas, and, perhaps more importantly, most blog readers and commentators do not seek to expose themselves to different and opposing points of view and arguments: blog readers do not take advantage of the diversity of the blogosphere and are perhaps trying to avoid opposing points of view, or just seeking to confirm their own.

In accordance with the main findings of this study, a simple analysis of political bloggers' posts indicates that they rarely (if ever) changed their points of view (as expressed by their posts) during the course of the electoral period debate, at least not a public manner. On the contrary, discussion seems to have contributed to the radicalization (polarization) of their points of view. This type of analysis is much more difficult to be made when it comes to blog readers (including commentators), since it is very easy to write comments anonymously and under different nicknames which makes it more difficult to analyze the evolution of participation.

\footnotetext{
${ }^{8}$ Network Address Translation.
} 
So, we are still far from understanding the real impact of the political blogosphere on bloggers, commentators, readers and society in general regarding preference formation and voting behavior. This study contributed to advance the knowledge in this area but certainly much more research still needs do be done.

The number of blogs that were analyzed, as much relevant as they were during the electoral period, limit the possibility to reach generalized conclusions. Future research must take into consideration a larger number of blogs, during a larger time framework, and covering also non-electoral periods. Also, further blog content analysis is necessary to ascertain the meaningfulness of posts and comments, in order to identify threads of discussions among blog writers and commentators, and to consider only meaningful posts and comments when analyzing links between blogs.

Tools such as Sitemeter can be used more extensively, but in order to get good quality data it is necessary to get blog administrators to collaborate, raising privacy issues (particularly of blog readers) and perhaps influencing bloggers behavior.

Pre and post discussion surveys could also be used to evaluate the impact of the blogosphere on blog readers. However, apart from practical (logistical) and representativeness issues, such methods would raise questions on how to isolate the specific impact of the blogosphere from the impact of other media and discussion forums (traditional media, discussions with family and friends, campaigning events, ...).

The fact that political blogs are getting ever more attention and exposure from the traditional media is a good indicator of their potential impact, but measuring such an impact on "silent" blog readers and society in general is still a challenging research task.

\section{References}

1. Barber, B.R.: Strong democracy: Participatory politics for a new age. University of California Press, Berkeley (1984)

2. Brants, K.: Guest Editor's introduction: the Internet and the public sphere. Political Communication 22, 143-146 (2005)

3. Habermas, J.: The Public Sphere: an encyclopedia article. New German Critique 3, 49-55 (1974)

4. Sunstein, C.R.: Republic.com. Princeton University Press, Princeton (2001)

5. Kemp, R.: Planning, public hearings, and the politis of discourse. In: Forrester, J. (ed.) Critical Theory and Public Life, pp. 177-201. The MIT Press, Cambridge (1988)

6. Fearon, J.D.: Deliberation as discussion. In: Elster, J. (ed.) Deliberative Democracy, pp. 44-68. Cambridge University Press, Cambridge (1998)

7. Dryzek, J.S.: Deliberative democracy and beyond: liberals, critics, contestations. Oxford University Press, Oxford (2000)

8. Stokes, S.: Pathologies of deliberation. In: Elster, J. (ed.) Deliberative Democracy, pp. 123-139. Cambridge University Press, Cambridge (1998)

9. Balkin, J.: What I learned about blogging in a year, http: / /balkin.blogspot.com/2004_01_18_balkin_archive.html\#10 7480769112109137

10. Woodly, D.: New competencies in democratic communication? Blogs, agenda setting and political participation. Public Choice 134, 109-123 (2008) 
11. Teachout, T.: Culture in the Age of Blogging. Commentary Magazine (2005)

12. Adamic, L., Glance, N.: The political blogosphere and the 2004 U.S. election: divided they blog. In: 3rd International Workshop on Link Discovery (LinkKDD '05). ACM, Chicago (2005)

13. Hargittai, E., Gallo, J., Kane, M.: Cross-ideological discussions among conservative and liberal bloggers. Public Choice 134, 67-86 (2008)

14. Witschge, T.: Online Deliberation: Possibilities of the Internet for Deliberative Democracy. In: Euricom Colloquium Electronic Networks \& Democratic Engagement (2002) 